\title{
A QUESTÃO DA ESPECIFICIDADE LITERÁRIA NA PRIMEIRA HISTÓRIA DA LITERATURA BRASILEIRA
}

\author{
Maria Cecília Boechat \\ UFMG
}

\begin{abstract}
RESUMO
Releitura da primeira História da literatura brasileira, defendendo a existência de uma teoria propriamente literária da literatura brasileira, o que a distingue de uma teoria da formação do povo brasileiro. Tentativa de demonstração de que, desde o início, nossa história da literatura dotou-se de exigências estéticas na eleição do corpus literário brasileiro.
\end{abstract}

\section{PALAVRAS - CHAVE}

História da Literatura, Literatura Brasileira, Sílvio Romero.

\begin{abstract}
"Nação primeiro, e progresso depois, às vezes agregados, são os motores e os cânones por excelência da historiografia que predominou ao longo do século XIX.

No final do século XX, quando a prática dos Estudos Culturais (Cultural Studies) se arrisca de novo a simplificar as relações entre literatura e sociedade, vale a pena retomar os nós conceituais da questão."
\end{abstract}

(Alfredo Bosi.)

$F_{\text {azendo frente ao espaço conquistado por uma parte do discurso pós-moderno, que }}$ nega a especificidade do literário e das literaturas nacionais, Alfredo Bosi chama a atenção para a importância do retorno da história literária à cena, hoje, dos estudos sobre literatura. ${ }^{1}$ Antes de tudo, porém, talvez seja necessário propor o retorno à história da literatura brasileira, no sentido de reavaliar pressupostos que se estabeleceram como tais para nós, seus herdeiros e estudiosos. Menos, porém, do que para um novo método de estudo historiográfico, e muito menos, ainda, que para tentar estabelecer um cânone "alternativo", talvez devamos retornar a nossa história literária para empreender uma releitura, indo a ela sem idéias preconcebidas e consolidadas.

Partindo ainda da citação em epígrafe, caberia reconhecer a unanimidade em torno da afirmação de que, inserida no projeto de construção das identidades nacionais, a

${ }^{1}$ BOSI, Alfredo. Por um historicismo renovado: reflexo e reflexão em história literária. In: Literatura e resistência, p. 7-53. 
historiografia literária do século XIX teria, no momento mesmo de sua formação, perdido a sua especificidade, traçando, não as histórias das obras literárias, mas as histórias das individualidades nacionais.

A historiografia brasileira, por sua vez, teria sofrido ainda mais duramente essa injunção. Seja porque às voltas com a literatura de um país recente, relativamente nova e considerada não de todo "madura", seja porque nas mãos de uma intelectualidade correlatamente fraca e, ainda, compromissada com a política imperial, ela teria abraçado mais fortemente o compromisso com o "projeto nação".

A comprovação parece simples: em nossa primeira história da literatura, Sílvio Romero afirma, abertamente:

"A história da literatura brasileira não passa, no fundo, da descrição dos esforços diversos do nosso povo para produzir e pensar por si; não é mais do que a narração das soluções diversas por ele dadas a esse estado emocional; não é mais, em outras palavras, do que a solução vasta do problema do nacionalismo [...]. Quer se queira, quer não, esse é o problema principal de nossas letras e dominará toda a sua história." ${ }^{2}$

Essa é, de fato, uma função que toda a nossa historiografia literária chamaria a si. Por sob métodos e pressupostos diversos, a história da literatura brasileira empenhou-se em definir o que seja literatura nacional e em selecionar e julgar obras e autores a partir desse critério. Não surpreende, portanto, que não apenas nossa historiografia literária oitocentista, mas toda a nossa história da literatura tenha sido cercada pela suspeita de ser pouco, ou não propriamente, literária. Como não surpreende, por extensão, que a produção literária tida como mais representativa do projeto nacionalista - nossa literatura romântica - tenha sido um dos maiores alvos da suspeita de ser igualmente pouco, ou não propriamente, literária. Que ela o tenha sido ou não, é uma questão irrelevante para o que aqui se quer indicar. É suficiente apenas constatar que a entrada e consolidação da produção romântica no cânone literário brasileiro deram-se justamente pela valorização de seu projeto nacionalista, como a confirmar a posição central ocupada por esse critério na historiografia literária brasileira. Entretanto, essa entrada e consolidação não se deram de modo tão tranqüilo como nos acostumamos a acreditar.

São famosos os ataques lançados por Sílvio Romero, em seus tempos de crítica aberta ao romantismo e a José de Alencar, que se firmaria como o "patriarca da literatura brasileira", e que é por ele julgado como "rebatedor de pastiches inconsistentes", fazendo coro com a suspeita quanto ao "estrangeirismo" do escritor.

Dizer que, em Sílvio Romero, a teoria da formação da literatura brasileira está vinculada a uma teoria da formação do povo brasileiro não constitui qualquer novidade, mas pode esclarecer parte da polêmica. Fundamentando sua teoria da formação do povo brasileiro no processo de mestiçagem - no que se aproxima do indianismo romântico -, Sílvio Romero discorda, entretanto, da interpretação etnológica romântica, a seu ver, equivocada, pela atribuição de uma importância indevida ao povo indígena nessa formação. Segundo sua teoria, no processo de mestiçagem - ainda a se completar, com a formação de um tipo homogêneo, de aspecto branco, resultado de um processo de melhoria das raças

${ }^{2}$ Romero, Sílvio. História da literatura brasileira, vol.II, p. 75. 
índia e negra -, os índios, já em decadência, seriam, assim como os caboclos, menos importantes nesse processo do que os negros, mais ativos e numerosos no cruzamento com a raça branca.

Vemos em debate, portanto, diferentes teorias antropológicas; mas este não é o único alvo do polemista, cuja discordância se dá também no campo propriamente literário. Positivista, Sílvio Romero insurge-se, necessariamente, contra o princípio metafísico da teoria poética romântica. Fundamentando sua teoria sobre o fazer literário em uma teoria organicista da arte, o romantismo finca o fenômeno literário no solo em que se desenvolve, ciente da particularidade das literaturas nacionais - que se diferenciam entre si por responderem a influências externas diversas -, mas, ao mesmo tempo, recusa-se a explicar o fenômeno da invenção literária por esses fatores. O momento de irrupção da invenção fica atribuído a um "não-sei-quê" fundador, que pode tomar diferentes feições, mas todas além do alcance da intenção, dos métodos ou regras, das explicações racionais. Usando a analogia de Herder, na semente já está a futura árvore, que entretanto se diferenciará de outras de um mesmo tipo de semente, mas de diferentes clima e solo. Assim se articulam, no romantismo, a consciência das leis internas de construção ficcional e o reconhecimento das influências externas - o senso do relativismo e uma "metafísica do absoluto".

Em contraposição, Sílvio Romero defende que os fatores deterministas - diferenças de solo, clima e raça - explicariam tanto a originalidade de cada poeta ou escritor quanto a especificidade das literaturas nacionais.

Além da discordância quanto à formação do povo brasileiro e quanto à teoria do fazer literário, o repúdio ao romantismo constitui-se, ainda, em uma postura política. A crítica de Sílvio Romero dirige-se não apenas ao projeto romântico em si, mas também aos escritores e ao sistema de legitimação literária. É o que fica claro em um de seus ataques a Alencar, em prol do elogio a Tobias Barreto:

"O Dr. Tobias é, entre nós, o mais completo tipo de escritor provinciano independente. Nunca fez romarias literárias à capital do império! É sabido quanto pesa essa lacuna. Não ter escrito para o Jornal do Comércio ou para o diário do Rio, não ter já sido visto por alguns conselheiros e dado o braço ao Sr. Alencar... oh! isto é uma falta imperdoável!”3

Curiosamente, pouco restará do polemista no historiador Sílvio Romero. Se, como crítico, atacara, em Alencar, o escritor consagrado, o representante das instituições culturais oficiais, outra será a sua postura como historiador. Uma explicação é apresentada pelo próprio autor, no Prólogo de sua História da literatura brasileira. Ali, sem renegar seus primeiros livros, caracteriza a nova obra como produto da maturidade, afirmando que, se perdia, nessa mudança, em termos de "reação e ataque", ganhava em "imparcialidade e moderação". 4 Araripe Jr. lembra, entretanto, que não se pode desconsiderar que o próprio crítico passa, nesse momento, por um processo de institucionalização:

${ }^{3}$ ROMERO, Sílvio. Apud ARARIPE JÚNIOR. Sílvio Romero polemista. In: BOSI (sel.e apres.) Araripe Júnior, p.335.

${ }^{4}$ ROMERO, Sílvio. História da literatura brasileira, vol.I, p. 21. 
"É bem verdade que o autor da História da literatura Brasileira não padece mais das exaltações dos tempos acadêmicos. O conceito público que atualmente cerca seu nome, a respeitabilidade inerente à posição de um dos membros mais conspícuos do magistério e o acatamento com que, em diversos círculos, é recebida sua palavra, apertam-no em uma esfera de ação mais cautelosa e o obrigam a uma vigilância sobre os próprios atos e discursos, a que dantes ele não se julgava obrigado, na qualidade de crítico demolidor. O escritor de hoje já tem uma obra a defender [...]."

De fato, na História de Sílvio Romero, é outra a imagem de Alencar; outra a avaliação do romantismo brasileiro. De início, a imaginação romântica de Alencar é como que desculpada, uma vez que seria compensada por um modo realista de representação. Para comprovar esse realismo, sua análise procura ressaltar índices da observação da realidade brasileira, cuja presença seria explicada por dados biográficos:

"Estudou com afinco os velhos cronistas e historiadores; procurou conhecer os costumes dos selvagens, o viver dos colonos, dos escravos, das classes dirigentes durante a formação das populações brasileiras; pôs em contribuição suas recordações próprias, já do que viu em suas viagens [...], já do que observou na vida social ou aprendeu de amigos sinceros, competentes conhecedores do país. ${ }^{6}$

A visão geral da obra de Alencar será aproximada, então, de um "retrato" do país em sua diversidade:

"Pode-se dizer que não ficou recanto do nosso viver histórico-social em que ele não tivesse lançado um raio de seu espírito [...]. A vida das cidades em diversas épocas e várias camadas da população está lá - em [...] Lucíola, Senhora; as cenas do existir dos selvagens puros - no Ubirajara e n'Os filhos de Tupã; dos índios em suas relações com os colonos nos primeiros séculos da conquista - em Iracema e n'O Guarani; as cenas originalíssimas dos pampas do sul - n'O Gaúcho [...] a sociedade colonial[...], alguns aspectos da escravidão [...]: os das fazendas das zonas das matas [...], feições várias do nosso labutar político $[\ldots] .^{7}$

A mudança é flagrante, e pode ser resumida na transformação do Alencar romântico em "realista"; do "rebatedor de pastiches inconsistentes" em escritor genuinamente nacional. E é com essa imagem que a literatura de Alencar se institucionaliza, por meio da História. Sua permanência canônica muito deve, então, a uma reconsideração das críticas sofridas quando da publicação das obras e sem dúvida responde ao interesse de Sílvio Romero em estabelecer uma tradição para a literatura brasileira. Sem dúvida, o historiador responde a necessidades do projeto nacionalista brasileiro, tratando-se, agora, não mais de negar, mas de justificar o caráter brasileiro da literatura de Alencar e de nosso romantismo. Isso não significa, porém, que as restrições à obra tenham simplesmente desaparecido; trata-se, antes, de uma reelaboração, que permite a passagem da crítica aberta ao acatamento condicionado.

Assim, Sílvio Romero mantém reserva quanto à qualidade da "primeira fase" da obra de Alencar - conhecida como a fase de "antes do ministério" (1852-68) -, no que ela seria,

\footnotetext{
${ }^{5}$ ARARIPE JÚNIOR. Sílvio Romero polemista. In: BOSI (sel. e apres.). Araripe Júnior, p. 321.

${ }^{6}$ ROMERO, Sílvio. História da literatura brasileira, vol.V, p. 74.

${ }^{7}$ ROMERO, Sílvio. História da literatura brasileira, vol.V, p. 75.
} 
segundo Sílvio Romero, "duma suavidade, duma doçura que chegava a enfarar”. Já a segunda fase - a de "depois do ministério" (1968-77) -, mais pessimista, para alguns, contaria, segundo o historiador, com obras "mais reais, mais humanas". ${ }^{8}$ As desilusões de Alencar como político explicariam, então, o que Sílvio Romero identifica como uma postura mais realista do escritor - menos fantasista, idealista ou metafísica -, como também faz com que o escritor apareça, agora, como aliado, não das instituições culturais oficiais, mas do próprio Sílvio Romero:

"A filáucia dos políticos de ofício e a grosseria dos intitulados chefes do regime imperial criaram-lhe grandes embaraços, fizeram-lhe baixas picardias. [...] A guerra foi cruel, porque, além das lides parlamentares, foram assalariados mastins para o atacarem nos domínios das letras. Teve isso a vantagem de despertar um Alencar desconhecido [o da segunda fase], vibrante de paixões, cheio de cóleras, despeitos e ironias. ${ }^{9}$

A mudança de avaliação da literatura de Alencar - da negação polêmica para a aceitação condicionada - deve, entretanto, ser explicada também pelos pressupostos teóricos que fundamentam o sistema historiográfico de Ślvio Romero. É preciso compreender, antes de tudo, que a literatura romântica realmente apresenta elementos que permitem a leitura do historiador. A tese da influência de fatores não-literários na diferenciação entre as literaturas nacionais - e que fundamenta a "sociologia biológica" de Romero - é uma tese romântica (Herder, $\mathrm{M}^{\mathrm{me}}$ de Staël, Chateaubriand). Ela explica a presença, na obra alencariana, do descritivismo realista e da cor local que permitem ao historiador ressaltar o "realismo" da obra de Alencar (e que compensaria seu "romantismo açucarado"). Fica assim resolvido o problema da imitação dos modelos franceses e é possível defender o caráter nacional de sua obra, a partir do princípio da representação das particularidades brasileiras.

Apenas parte da literatura de Alencar, ou de nossa literatura romântica, portanto, seria devedora de indesejadas influências estrangeiras: não o "sentimento", nem o "assunto", ambos particulares, nacionais, mas o "trato" com o assunto, ou seja, a forma romântica, essa, sim, perigosamente próxima dos modelos franceses, senão explicitamente imitada. Para que Alencar passe de "rebatedor de pastiches" a um dos "fundadores da literatura brasileira”, será preciso, então, apenas um passo: basta que, nesse trajeto, a parte devedora seja subtraída. E o que resta, desconsiderado o modo romântico (idealizante, exagerado) de tratar o assunto brasileiro, pode então aparecer: o "sentimento nacionalista" e o "realismo" das descrições da realidade brasileira, os "retratos" que o escritor soube fazer de "nosso viver histórico-social."

Interessante observar, ainda, que, ao mesmo tempo em que o romantismo não é renegado em bloco, a crítica ao indianismo também se torna mais pontual na História. Não se coloca mais em dúvida seu sentido nacionalista, a despeito de sua incorreção etnológica. Questiona-se, agora, apenas o predomínio do tema na literatura brasileira e sua eleição como critério de aferição de nacionalismo literário:

"Teria sido uma lacuna imperdoável se esses dois grandes agitadores da literatura brasileira [Gonçalves Dias e José de Alencar] tivessem olvidado os índios; teria sido

\footnotetext{
${ }^{8}$ ROMERO, Sílvio. História da literatura brasileira, vol.V, p. 76-7.

${ }^{9}$ ROMERO, Sílvio. História da literatura brasileira, vol.V, p. 76-7.
} 
censurável curteza de vistas, se nos quisessem perpetuamente molestar com eles[...]. Eu bem sei que houve aí uma hora de desvairamento em que se quis pregar como verdade absoluta só ser brasileira a produção que cheirasse a caboclos." ${ }^{10}$

Sílvio Romero reivindica um novo sentido para o nacionalismo literário, redefinindoo nos seguintes termos:

Veja-se bem: não é que os assuntos indianos, africanos, sertanejos, matutos, tabaréis, regatões, etc., devam ser banidos de nossa poesia. Não: na poesia há lugar para cem sistemas e duzentos estilos [...]. O que eu desejo é que o nacionalismo passe do anelo vago para o fato subjetivo, que ele pareça espontâneo. O poeta pode mostrar-se brasileiro tanto no manejo de um assunto geral, universal, quanto no trato de assuntos nacionais. ${ }^{11}$

Nessa perspectiva, estritamente literária, o romantismo brasileiro não teria sido tão nacional quanto pretendera porque, preso à representação da paisagem e de assuntos locais, teria sido incapaz de garantir o "trato" particular, não só de temas universais, mas dos próprios assuntos nacionais. Ou seja: ainda que de correto "anelo" nacionalista, nossa literatura romântica não teria conseguido elaborar uma forma particular, nacional, de literatura. O que incomoda, portanto, ao historiador, em relação ao romantismo brasileiro, não diz respeito a uma questão ideológica ou antropológica, mas a uma questão propriamente estética.

Surpreendentemente, encontramos aqui um Sílvio Romero muito mais formalista do que sugere o conceito de literatura com que fundamenta sua História, que sabemos amplo e indistinto em relação à filosofia, à crítica, à história e à política, e do que poderíamos imaginar tendo em vista sua teoria social-biológica.

De fato, a argumentação guarda muita proximidade com o famoso ensaio de Machado de Assis, "Instinto de nacionalidade" (1873), que se firmou como sendo a primeira elaboração de um conceito de nacionalismo literário propriamente estético-formal. Essa proximidade foi indicada por Antonio Candido ${ }^{12}$, mas é pouco comentada pelos estudos historiográficos atuais.

Pode nisso ter contribuído a postura polêmica assumida por Sílvio Romero em relação a Machado de Assis, e que, apesar da mudança de posição na História, parece ter-se fixado na posteridade. Não menos, e até mais importante para explicar esse "esquecimento", porém, é o julgamento que se estabeleceu sobre sua História - de que seria mais historicista do que literária. Nessa perspectiva, a aproximação entre Romero e Machado pode parecer totalmente inadequada.

Acatada, porém, a possibilidade de que o primeiro historiador da literatura brasileira possa apresentar alguma consciência do fenômeno literário, seria sensato pensar nas conseqüências dessa perspectiva renovada.

Para a própria sistematização do historiador, isso significa reconhecer que sua teoria da formação do povo brasileiro - que previa a prevalência do "aspecto branco" - não pode

${ }^{10}$ ROMERO, Sílvio. História da literatura brasileira, vol. III, p. 238.

${ }^{11}$ ROMERO, Sílvio. História da literatura brasileira, vol. II, p. 75-6.

${ }^{12}$ CANDIDO, Antonio (sel. e apres.). Sílvio Romero, p. 25. 
simplesmente ser transposta para a teoria estética: a prevalência de uma "forma branca" (leia-se "européia”) não se reveste de positividade, como na teoria étnica, pela própria lógica da imitação e da influência que, no século XIX, exige a diferenciação formal das literaturas nacionais. $\mathrm{O}$ que é bom para a raça, portanto, não o seria para a literatura. Assim se explicam as restrições de Sílvio Romero ao projeto literário de nosso romantismo, que só se salva por sua contrapartida, o projeto nacionalista.

Para a historiografia literária brasileira, por sua vez, a conseqüência é que devemos reconhecer que o conceito de literatura nacional, desde o início, não está desvinculado do estabelecimento de exigências estético-formais. Assim, devemos reconsiderar a premissa de que nossa primeira história da literatura brasileira, por abraçar o projeto nacionalista, teria optado por um critério, ou valor, mais político-ideológico do que estético - o que explicaria, no caso de nosso romantismo, que uma literatura considerada esteticamente deficiente tivesse garantido seu lugar no cânone literário brasileiro. É possível pensar, ao contrário, que é justamente porque desconfia da literatura romântica - segundo Sílvio Romero, dependente das soluções estéticas francesas - que a primeira história da literatura brasileira se vê levada a lançar mão de outros valores - como o da "consciência nacional" - para afirmar a existência de uma tradição literária no país. Forçoso é reconhecer que as restrições ao romantismo brasileiro em nossa história literária ${ }^{13}$ não decorrem propriamente de uma teoria tosca sobre o fenômeno literário: em Sílvio Romero, encontramos já a consciência de que o vínculo entre literatura e sociedade não se estabelece como uma relação direta, na observação e descrição da realidade, mas como relação intermediada pelo texto; que uma literatura, para ser nacional, demanda a conquista de um "modo", de uma forma própria de expressão literária. Para isso nos adverte o fato de que o romantismo brasileiro, embora responda ao quesito da consciência nacionalista, tenha, ainda assim, constituído problema para nossa história da literatura.

A ênfase na dimensão político-ideológica do romantismo brasileiro, portanto, apenas aparentemente confirmaria a prevalência desses valores como critérios historiográficos. Pode-se argumentar, ao contrário, que, justamente por ter adotado critérios propriamente estéticos é que, frente a uma literatura tida como esteticamente desqualificada - pecha, afinal, sofrida não apenas pelo romantismo brasileiro -, nossa historiografia literária foi levada a recorrer a outros critérios para reconhecer e legitimar uma tradição literária brasileira.

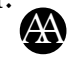

${ }^{13}$ Em sua História da literatura brasileira, José Veríssimo é assertivo: "Pecam [os nossos escritores românticos] pelo excesso de sentimentalismo e de romanesco que, principalmente na ficção em prosa, roça neles pela pieguice e pelo amaneiramento do pensamento e da expressão [...]. Não têm ainda as preocupações de forma que chamamos de artísticas." VERÍSSIMO, José. História da literatura brasileira, p. 143. Frente a uma desqualificação estética tanto mais comprometedora quanto mais explícita a exigência estética historiográfica, José Veríssimo adota estratégia semelhante à de Súlvio Romero, mas de maior radicalidade: considera existir literatura nacional desde o romantismo, mas como mero reflexo da independência política. Cf. VERÍSSIMO, op. cit, p. 23. 


\section{A BSTRACT}

The article discusses the first História da literatura brasileira [History of Brazilian Literature] and claims the existence of a theory of Brazilian literature that is literary per se, and thus not a theory of the development of the Brazilian people. The article attempts to demonstrate that, from the beginning, the history of our literature was aesthetically demanding in its selection of a corpus of Brazilian literature.

\section{KEYWORDS}

Literary History, Brazilian Literature, Sílvio Romero.

\section{REFERENCIAS BIBLIOGRÁFICAS}

ABRAHMS, M. H. El espejo y la lámpara: teoría romántica y tradición crítica acerca del hecho literário. Buenos Aires: Nova, 1962.

BOSI, Alfredo. (sel. e apres.) Araripe Júnior: teoria, crítica e história literária. Rio de Janeiro: Livros Técnicos e científicos; São Paulo: Ed. da Universidade de São Paulo, 1978.

BOSI, Alfredo. Literatura e resistência. São Paulo: Companhia das Letras, 2002.

CANDIDO, Antonio. (sel. e apres.) Sílvio Romero: teoria, crítica e história literária. Rio de Janeiro: Livros Técnicos e científicos; São Paulo: Ed. da Universidade de São Paulo, 1978. ROMERO, Sílvio. História da literatura brasileira. 3 ed. Rio de Janeiro: José Olympio, 1943. 5 v. VERÍSSIMO, José. História da literatura brasileira. 4 ed. Brasília: Ed. Universidade de Brasília, 1981. 